\section{International Scientific Journal Theoretical \& Applied Science}

Dmitry Nikolayevich Chernov

Associate professor, candidate of psychological sciences,

Professor of the Department of general psychology and pedagogic,

Pirogov Russian National Research Medical University, Moscow, Russia chernov_dima@mail.ru

Year: 2017 Issue: $05 \quad$ Volume: 49

Published: $30.05 .2017 \quad$ http://T-Science.org

SECTION 21. Pedagogy. Psychology. Innovations in the field of education.

\title{
SOCIOCULTURAL CONDITIONS OF LANGUAGE ACQUISITION IN A SITUATION OF EMIGRATION
}

Abstract: This paper analyzes the sociocultural macro conditions of life of the families of German immigrants from Kazakhstan to Germany, which are reflected on the difficulties not only in the preservation of the Russian language and culture among children from displaced families, but in the mastery of the German language. The role of the formation of a balanced bilingualism in children for the development of bicultural personality and the need for consultation and preventative work with parents of children with different motives and attitude to the preservation of the Russian language in their children are discussed.

Key words: bilingualism, bicultural personality, culture, speech, language, language competence.

Language: Russian

Citation: Chernov DN (2017) SOCIOCULTURAL CONDITIONS OF LANGUAGE ACQUISITION IN A SITUATION OF EMIGRATION. ISJ Theoretical \& Applied Science, 05 (49): 8-13.

Soi: http://s-o-i.org/1.1/TAS-05-49-2 Doi: crossef https://dx.doi.org/10.15863/TAS.2017.05.49.2

\section{СОЦИОКУЛЬТУРНЫЕ УСЛОВИЯ ОВЛАДЕНИЯ ЯЗЫКОМ В СИТУАЦИИ ЭМИГРАЦИИ}

Аннотация: В работе проанализированы социокультурные макроусловия жизни семей немецчких переселенцев из Казахстана в Германии, которые отражаются на трудностях не только в сохранении русского языка и русскоязычной культуры у детей из семей переселенцев, но и в овладении ими немецким языком. Обсуждается роль формирования сбалансированного билингвизма у детей для становления бикультуральной личности и необходимость консультациионно-профилактической работы с родителями детей, имеющими разные мотивы и установки на сохранение русского языка у своих детей.

Ключевые слова: билингвизм, бикультуральная личность, культура, речь, язык, языковая компетеничия.

\section{Introduction}

Одной из важнейших проблем современной психолингвистики является изучение становления речи у детей в билингвальной среде. Недостаточно изучены социокультурные условия сохранения у ребенка родного языка родителей в ситуации эмиграции. Формирование у детей знания нескольких языков позволяет развить толерантность к различным культурам. Если дети - потомки эмигрантов, то сохранение у ребенка языка страны, из которой приехали родители, позволяет воспитать интерес к культуре данной страны, сформировать бикультуральную личность - личность, в которой сосуществуют формы двух различных культур. Каждый индивид, являющийся субъектом более чем двух культур, тем самым обогащает свой духовный мир, решая проблемы сопряжения различающихся ценностей, установок, знаний, традиций и т.д. Однако часто особенности социокультурной ситуации развития таких детей препятствуют формированию у них полноценного билингвизма. Как указывает Н.Б. Михайлова: «Ситуация эмиграции является для человека экстремальной, она требует психологической готовности к жизни в совершенно новых социальных условиях» $[1$, с. 26]. Адаптация к ситуации эмиграции осложняется плохим знанием языка, что ограничивает возможности трудовой деятельности и общения. Сталкиваясь с трудностями адаптации к социокультурным условиям жизни в новой стране, переселенцы замыкаются в рамках диаспоры, что негативно сказывается на усвоении и языка принимающей 
стороны, и сохранении родного языка. Эта проблема актуальна для казахстанских немцев.

\section{Materials and Methods}

В нашей работе мы проанализировали макроструктурные особенности социокультурной ситуации сохранения русского языка у детей из семей немецких переселенцев из Казахстана, проживающих в Германии. Для эмпирической проверки имеющихся литературных данных мы использовали результаты опроса 60 матерей, казахстанских немок в возрасте от 22 до 35 лет, в основном, проживающих в земле БаденВюртемберг, полученные нами в ходе исследования качества русской речи младших дошкольников из этих семей [2].

Еще Л.С. Выготский указывал на то, что невозможно понять, какое значение для психического развития ребенка имеет двуязычие без анализа конкретных условий, в которых происходит развитие ребенка [3]. По мнению А.А. Залевской современные данные изучения билингвизма не могут быть адекватно проинтерпретированы без включения в логику анализа «внешних» (социокультурных) и «внутренних» (психологических) факторов [4]. Такая позиция неизбежно приводит исследователя к необходимости изучения ребенка-билингва как развивающейся личности и субъекта в конкретных социокультурных условиях и анализа этих условий.

В настоящее время в Германии проживает достаточно много казахстанских немцев. Только в период 1990-1998 гг. Германия приняла 275 тыс. переселенцев - русских немцев (Spätaussiedler - «поздних переселенцев») в возрасте 15-25 лет, которые слабо владели немецким языком, интеграция их в немецкое общество до сих пор остается больным вопросом [5]. На 1999 г. в Германии зарегистрировано около 1 млн. русских немцев-переселенцев [1]. По последним данным в Германии проживает около 750 тыс. казахстанских немцев [6]. С началом их массового прибытия в Германию, возникла проблема: при необходимости изучения немецкого языка и последующей аккультурации значительная часть репатриантов стремилась сохранять культурные традиции бывшей Родины и культивировать русский язык у своих детей. По результатам проведенного нами опроса молодых матерей-немок, эмигрировавших из Казахстана, $66,7 \%$ респондентов указали, что желают сохранить русский язык у детей. Однако причины этого желания разнообразны: от упрощения внутресемейного общения (родители плохо владеют немецким языком, 30\%) до стремления привить ребенку русскоязычную культуру (36,7\%). Ключом к пониманию таких разноуровневых мотивов может стать изучение особенностей социокультурной макроситуации, в которой сохраняется русский язык в семьях казахстанских немцев, проживающих в Германии. Это необходимо для выработки правильной позиции в консультационнопрофилактической работе с такими семьями с целью успешной аккультурации в новом социуме. Важно понять, не только то, в каких социокультурных макроусловиях семьи развивается детский билингвизм детей из семей казахстанских немцев, проживающих в Германии, но и проанализировать, в каких социокультурных макроусловиях развивался билингвизм родителей этих детей в Казахстане.

Появление этнических немцев на территории Казахстана было связано как с естественной миграцией, так и с массовой депортацией в начале 40-х гг. XX в. Депортация привела к увеличению численности немцев на территории Казахстана в десятки раз. По данным последней переписи населения, проведенной в Советском Союзе в 1989 г., в Казахстане было зарегистрировано $957 \quad 518$ постоянно проживающих немцев [7]. При такой внушительной численности культура немцев Казахстана оказалась плохо изученной. В советское время бедность знаний о культуре этой этнической группы была обусловлена идеологическими причинами. Однако такое положение сохраняется и в современном постсоветском Казахстане [там же]. Именно национальная культура является способом сохранения и формирования национальной идентичности, ценностей и нравственных идеалов, позволяет регулировать мышление отдельного субъекта и строить отношения с другими этническими группами. Язык является важнейшим средством воспроизводства и общечеловеческой культуры, и национальной, в частности. К сожалению, исследователи отмечают, что в группе казахстанских немцев многие десятилетия происходит процесс вытеснения родного языка русским, немецкая молодежь не заинтересована в изучении родного языка. В.А. Штаб показал, что в Казахстане у немцев русский язык вступает с немецким в ряд оппозиционных взаимодействий:

- Немецкий литературный язык взаимодействует с русским литературным языком, что характерно для хорошо образованных казахстанских немцев. При этом может наблюдаться и свободное владение родным диалектом.

- Немецкий литературный язык взаимодействует с обиходно-разговорным русским языком, что типично для проживания этнических немцев в сельской местности. Именно в такой ситуации немецкий язык становится вторичным даже в ситуациях бытового 
взаимодействия. Хотя встречаются случаи, когда в бытовом взаимодействии сохраняется родной диалект.

- Чаще всего встречается взаимодействие местного немецкого диалекта с обиходноразговорным языком [8].

Именно две последних социокультурных ситуации характерны для взаимодействия русского и немецкого языков у большинства казахстанских немцев. Сохранение литературного нормативного языка в ситуации растворенности малого этноса в большом требует определенных условий: наличие периодических изданий, радио и телевещания на родном языке, театральной жизни, развития науки, литературного художественного творчества и т.п. Однако, важнейшим (если, не главным) условием является человеческий фактор: литературный нормативный язык, как правило, воспроизводится носителями языка, обладающими высоким уровнем внутренней культуры и образованности, способными культивировать в сознании этноса представление об уникальности национальной культуры и языка, его престижности, что характерно для интеллигенции. В силу идеологических причин сохранение слоя интеллигенции среди казахстанских немцев оказалось затруднено. Этому способствовали и трудности в получении высшего образования казахстанскими немцами. По-видимому, этот фактор, наряду с востребованностью именно русского языка в процессе повседневной жизнедеятельности, привел к вытеснению немецкого языка, а значит, - к ассимиляционным процессам в культуре.

Обнаружено, что у разных поколений этнических немцев билингвизм существует в неодинаковых формах. Например, в группе немецких поселенцев на Алтае среди старшего поколения немецкий язык выполняет комплементарную функцию по отношению к русскому. Такой вариант взаимодополняющего билингвизма стабильно наблюдался долгое время, поскольку все носители диалекта изучали в национальных школах немецкий литературный язык. Среди среднего поколения русский язык постепенно берет на себя коммуникативные функции немецкого языка, в силу чего последний оказывается излишним. У младшего поколения немецкий язык практически полностью вытеснен русским. При межпоколенном общении пожилые люди склонны разговаривать с внуками понемецки, в то время как для внуков основным языком является русский. Как заключает Л.И. Москалюк, «у большинства представителей молодого поколения обнаруживается явление редукции во всех языковых областях. Это выражается в ограниченном словаре, морфологических упрощениях, бросающихся в глаза повторах, стереотипных образцах предложений» [9, с. 22].

Многими исследователями отмечается, что развитие немецкого языка в ситуации проживания этнических немцев на русскоговорящих территориях (в Казахстане, в России - в Кировской области, Поволжье, на Алтае) в корне отличается от социокультурных ситуаций проживания немцев на территориях, прилегающих к ФРГ: в провинции Альто-Адидже (Италия), Эльзасе и части Лотарингии (Франция), в районе Ареля, Аубеля, Эйпена, Мальмеди и Сен-Вита (Бельгия). В Европе диалекты формируются во взаимодействии с немецкой культурой, реализуемой посредством нормативных форм немецкого языка [10]. Заимствования из русского языка приводят к использованию в немецком обиходноразговорном языке (на примере немцев Кировской области) слов, лексически и грамматически подобных русским словам: kvarti:r - квартира, serno - зерно, kastrolie кастрюля; babuška - бабушка и др. Происходит вкрапление их в структуру немецкого языка: изменения обнаружены при оформлении числа («dr pamidor»-di: pamidoren, «die Tomate» - die Tomaten), склонении существительных («in $d r$ banja» - im Dampfbad), образовании глаголов («geremonti:rt» - renovieren - pyc. ремонтировать) [11]. В ходе исследования диалекта поволжских немцев было обнаружено использование в речи большого количества оборотов с различными русскоязычными вкраплениями, например: «Die wollte die Leit mit Nitschewo fittre» («Она хотела морить людей голодом»). Вместо немецкого Nichts использовано русское «ничего» [12]. Ученые давно пришли к выводу, что просторечие, в отличие от литературного языка или стандартизированного диалекта, не стабилизировано, обладает ограниченной лексикой; взаимная интерференция просторечивых форм еще больше дестабилизирует расплывчатые нормы речевого узуса, что еще более отдаляет речь человека от литературных форм [13].

Таким образом, к моменту переселения, как правило, молодых русских немцев в Германию знание немецкого языка ограничивалось немецким диалектом обиходно-разговорного характера при тотальном доминировании русского языка. По данным нашего опроса, 93\% матерей-немок считают родным языком русский; среди отцов процент составил 97\%. По свидетельству многих переселенцев, опрошенных нами, на момент переселения они практически не знали немецкий язык.

До середины 80-х гг. XX в. в Германии существовало в целом положительное отношение 
к немецким эмигрантам из СССР. Ситуация изменилась с резким ростом числа эмигрантов из России и стран бывшего СССР. Причины негативного отношения зачастую оправданы. В силу стрессового характера ситуации эмиграции иммигранты зачастую стараются поддерживать тесные личные взаимоотношения друг с другом, заключать внутри- и межнациональные браки, создавать общественные, национальные объединения (общины, землячества). В их среде доминирует преимущественно свой уклад жизни, свойственный тому, что был на Родине [14].

Н.Б. Михайловой было проведено психологическое исследование ситуации эмиграции, в которой оказались русские немцы. Оно показало, что в первые месяцы переселенцы испытывают страх, смятение, у них отсутствуют четкие представления о том, как жить дальше, преобладают негативные переживания, связанные с разрывом интерперсональных связей, сложившихся в Казахстане. Спустя два года у иммигрантов наблюдается снижение агрессивности и удовлетворенность жизнью, возникает свойственная немецкому обществу ориентация на выполнение правил, но растет ощущение перегруженности требованиями и каждодневного стресса. Индивиды ориентированы на принятие любой работы, без претензий на социальную позицию [1]. По причине того, что среди переселенцев с постсоветского пространства проблема безработицы стоит очень остро, и, кроме того, в последнее время в Германии наблюдается высокий процент безработицы среди трудоспособного немецкого населения, по нашим данным, многие матери, по сути своей, являются домохозяйками (43,3\% матерей). Т.е. эти матери, как правило, имеют широкие возможности для организации целенаправленного культурного и языкового воспитания своих детей. Профессиональная незанятость матерей не отражается на материальном положении семей оно, как правило, среднее, хотя в 26,7\% случаях матери указали, что материальное положение их семей - выше среднего. 50\% матерей имеют среднее образование, $10 \%$ - неполное среднее, только 30\% матерей имеют законченное высшее образование, остальные матери образование не завершили, или завершают.

Как показывают исследования, проведенные в Германии и других странах, при достаточно либеральных условиях жизнедеятельности первое поколение иммигрантов отнюдь не стремится к интеграции в новое общество. Во втором поколении обычно противодействие ассимиляции становится менее выраженным. Третье поколение иммигрантов уже активно ассимилируется в общественную жизнь принимающей стороны [14]. Ассимиляционные процессы можно наблюдать у детей из семей немецких переселенцев из Казахстана. Отсутствие речевой компетентности является важнейшей проблемой переселенцев в Германии. Как показывают исследования Н.Б. Михайловой, в первое время русские переселенцы испытывают настоящий шок, поскольку никак не могут выразить свои потребности и желания хотя бы в простых речевых формах и не понимают того, что говорят другие. Усвоение языка оказывается для русских немцев крайне сложной задачей, трудность которой изначально недооценивалась. При всем этом знание иммигрантами немецкого языка не является в Германии каким-то особым достижением, немецкий язык является непременным условием трудоустройства. После нескольких лет проживания в новых условиях иммигранты обычно овладевают языком принимающей стороны, но общение на нем с коренным населением воспринимается как тяжкая необходимость, отсутствует собственное стремление к овладению немецким языком, многие стремятся ограничить свою языковую компетентность владением лексическим минимумом, обеспечивающим решение проблем, связанных с элементарными жизненными потребностями [1]. Из 60 опрошенных нами матерей-немок, $76 \%$ спустя 4 и более лет проживания в Германии считают, что свободно владеют немецким языком, 17\% матерей-немок испытывают затруднения в использовании немецкого языка, 7\% матерей до сих пор практически не знают языка и взаимодействуют с окружением на русском языке. Среди отцов наблюдается аналогичная ситуация. Необходимо понимать, что реальное тестирование языковой компетенции может показать и иные результаты, поскольку ситуация опроса может быть отнесена к разряду таких, результаты которых могут восприниматься респондентами как способные потенциально повлиять на их жизнь.

С увеличением кол-ва иммигрантов в Германию пришло осознание, что существует достаточно большая категория «иностранных» детей, которые должны быть социализированы. Стала успешно развиваться концепция интеркультурного образования, целью которого явилось органичное усвоение культуры принимающей стороны при сохранении национальной культуры. Кроме того, идея поликультурного образования подразумевает формирование интеркультурной компетенции у любого жителя Германии на основе уважения личности любой национальности. Предполагалось, что « ... если иммигранты овладеют в достаточной степени интеркультурной компетенцией, они будут в состоянии сделать продуктивный выбор интеграцию, а титульная нация, владея 
интеркультурной компетенцией, сможет быть толерантной к чужим» [5, с. 95]. В 90-х гг., в Германии (в частности, в Берлине) были открыты государственные европейские школы (например, немецко-русские), в которых развиваются идеи билингвального образования. Дети овладевают языками-партнерами, знакомятся с культурой изучаемых языков. Эти школы являются важной моделью формирования поликультурной компетенции детей [15].

Описывая ситуацию билингвального развития детей из немецких семей переселенцев из Казахстана, О.В. Бернгардт пишет: «Дети, родившиеся в этих семьях, воспитываются уже на новой родине в среде, где сохраняется русский язык и русские обычаи и традиции. Для таких детей русский язык является «домашним» обиходно-разговорным, а немецкий - языком, на котором происходит обучение и общение с немецкоговорящими сверстниками» [16, с. 3]. В силу престижного характера немецкого языка для немецких детей из таких семей доля русского языка в межличностном общении в семье и с окружающими людьми должна уменьшаться. Однако, в силу различных причин (с одной стороны, стремление привить русскую культуру ребенку, с другой стороны - облегчить общение с миром через изучающего немецкий язык ребенка), некоторые родители стремятся к сохранению русского языка у их детей.

\section{Conclusion}

В ситуации эмиграции при плохой адаптации в немецкое социокультурное пространство родителей детей описанные условия могут негативно повлиять на становление и русского, и немецкого языков у детей, родившихся в Германии. Анализ этих условий важен для коррекционнопрофилактической работы с детьми и разработки различных стратегий консультационных мероприятий, адресованных родителям немецких младших дошкольников из семей переселенцев с постсоветского пространства с целью формирования сбалансированного руссконемецкого билингвизма. Семьям, в которых родители, как правило, осознают необходимость изучать немецкий язык и стремятся стать частью немецкого общества, но при этом стремятся сохранить русский язык у своих детей, необходима систематическая поддержка со стороны общественных организаций, содействующих популяризации русской культуры и языка за рубежом. У детей из этих семей есть все шансы овладеть двумя языками и двумя культурами, т.е. стать не только билингвами, но и бикультуралами. С родителями же, которые, приехав в Германию, сформировали рентную установку, стремятся к общению в узком кругу себе подобных, поощряют у ребенка изучение русского языка в ущерб немецкому, реализуя тем самым эгоистические мотивы, требуется специальная консультационнопрофилактическая работа. Цель этой работы актуализация мотивов гражданственности, стремления врасти в общество, осознание значимости изучения немецкого языка для адекватной аккультурации. В этом случае ребенок станет полноценным гражданином страны, но при этом, будет воспитываться в духе взаимообогащающего влияния разных культур и языков. В семьях, в которых родители сознательно стремятся к ассимиляции, возможна просветительская работа, побуждающая родителей поставить под сомнение отказ от своего прошлого - культуры и языка. Необходимо показать, что правильно организованная психолого-педагогическая работа по развитию двух языков у ребенка с младенчества впоследствии дает ему преимущества в когнитивном и личностном развитии. Ради обогащения личности подрастающего человека родителям не стоит пренебрегать естественно сложившимися условиями формирования многоязычия у ребенка. Подобная консультационная работа, конечно же, может носить рекомендательный характер.

\section{References:}

1. Mihajlova NB (2000) Psihologicheskoe issledovanie situacii jemigracii // Psihologicheskij zhurnal. - 2000. - T. 21. - № 1. - p. 26-37.

2. Chernov DN (2010) Sociokul'turnaja obuslovlennost' razvitija russkoj rechi u detej v situacii jemigracii // Psihologija obrazovanija v polikul'turnom prostranstve. - 2010. - T. 3. № 3. - p. 75-81.

3. Vygotskij LS (1980) K voprosu o mnogojazychii v detskom vozraste // Hrestomatija po vozrastnoj i pedagogicheskoj psihologii. - M.: Izd-vo MGU, 1980. - p. 6772. 


\begin{tabular}{l|lrl|l|ll} 
& ISRA (India) & $=\mathbf{1 . 3 4 4}$ & SIS (USA) & $=\mathbf{0 . 9 1 2}$ & ICV (Poland) & $=\mathbf{6 . 6 3 0}$ \\
Impact Factor: & ISI (Dubai, UAE) $=\mathbf{0 . 8 2 9}$ & PUHL (Russia) $=\mathbf{0 . 2 3 4}$ & PIF (India) & $=\mathbf{1 . 9 4 0}$ \\
& GIF (Australia) & $\mathbf{0 . 5 6 4}$ & ESJI (KZ) & $=3.860$ & IBI (India) & $=\mathbf{4 . 2 6 0}$ \\
& JIF & $=\mathbf{1 . 5 0 0}$ & SJIF (Morocco) & $=\mathbf{2 . 0 3 1}$ & & \\
\hline
\end{tabular}

4. Zalevskaja AA (1999) Vvedenie V psiholingvistiku. - M.: Izd-vo RGGU, 1999. $382 \mathrm{p}$.

5. Lavrova TB (2006) Interkul'turnoe obrazovanie v Germanii // Obrazovanie i nauka. - 2006. № 5. - p. 93-100.

6. Piskorskaja L (2009) Germanija stanovitsja blizhe // Megapolis. - 2009. 10.08.2009. [Jelektronnyj resurs]. Available: http://megapolis.kz/art/Germaniya_stanovitsya_ blizhe (Accessed: 15.03.17).

7. Efremova-Shershukova NA (2009) Problemy razvitija kul'tury nemcev Kazahstana v poslevoennoe vremja $\mathrm{v}$ otechestvennoj istoricheskoj literature // Vestnik Tomskogo gosudarstvennogo universiteta. - 2009. - № 323. - p. 141-143.

8. Shtab VA (1990) Sociolingvisticheskoe issledovanie jazyka nemcev v Kazahstane: dis. ... kand. filol. nauk. - M.: MGU, 1990. - 147 p.

9. Moskaljuk LI (2000) Jazykovye kontakty v nemeckih selah na Altae // Jazyk i kul'tura rossijskih nemcev. Sprache und Kultur der Russlanddeutschen. Sb. nauch. trudov. Vyp. 2. - Saratov: izd-vo Saratovskogo un-ta, 2000. p. 17-24.

10. Bajkova OV (2009) Variativnost' jazyka nemeckih poselencev $\mathrm{v}$ uslovijah inojazychnogo okruzhenija // Vestnik Cheljabinskogo gosudarstvennogo universiteta. - 2009. - № 35. - p. 14-19.

11. Bajkova OV (2007) Zaimstvovanija v rechi rossijskih nemcev Kirovskoj oblasti // Vestnik
Cheljabinskogo gosudarstvennogo universiteta. - 2007. - № 15. - p. 15-19.

12. Sal'kova NE (2000) Poslovicy i pogovorki nemcev Povolzh'ja // Jazyk i kul'tura rossijskih nemcev. Sprache und Kultur der Russlanddeutschen. Sb. nauch. trudov. Vyp. 2. - aSaratov: izd-vo Saratovskogo un-ta, 2000. p. 29-35.

13. Bogus MB (2008) Vlijanie bilingvizma na intellektual'noe razvitie lichnosti obuchaemyh // Vestnik Adygejskogo gosudarstvennogo universiteta. Serija «Pedagogika i psihologija». - Majkop: Izd-vo AGU, 2008. - № 7. - p. 4044.

14. Liukkonen EV (2009) Osobennosti jetnosocial'noj integracii immigrantov iz Rossii // Uchenye zapiski Sankt-Peterburgskogo gosudarstvennogo instituta psihologii $\mathrm{i}$ social'noj raboty. -2009 . - T. 11. - № 1. - p. 137-141.

15. Bljajl' M, Sulejmanov I (2009) Bilingval'noe obrazovanie v nachal'noj shkole Germanii. Gosudarstvennye evropejskie shkoly g. Berlina // Nachal'naja shkola. - 2009. - № 7. - p. 9296.

16. Berngardt OV (2009) Rech' rebenka-bilingva kak predmet leksikograficheskogo opisanija (situacija russko-nemeckogo dvujazychija): avtoref. ... dis. kand. filol. nauk. - Jaroslavl'.: JarGPU im. K.D. Ushinskogo, 2009. - 22 p. 